\title{
PERCEPÇÕES DA EQUIPE TÉCNICA ESCOLAR E DAS FAMÍLIAS DOS EDUCANDOS NUMA ESCOLA DE REFERÊNCIA DO RIO DE JANEIRO SOBRE BULLYING E O PAPEL DA ORIENTAÇÃO EDUCACIONAL
}

\section{PERCEPTIONS OF THE SCHOOL TECHNICAL STAFF AND FAMILIES OF THE STUDANTS IN A REFERENCE SCHOOL IN RIO DE JANEIRO ON BULLYING AND THE ROLE OF EDUCATIONAL GUIDANCE}

\author{
MARTINS, Ana Carolina Hyer de Faria da Silva ${ }^{1}$ \\ BARREIROS, Cláudia Hernandez ${ }^{2}$
}

\begin{abstract}
RESUMO
Este artigo foi construído a partir da pesquisa de mestrado que resultou na elaboração da dissertação intitulada "'Nem sempre o adulto resolve': o serviço de orientação educacional e as práticas de bullying no primeiro segmento do ensino fundamental.". O recorte elaborado destaca 1) as percepções da equipe escolar e dos responsáveis de educandos sobre o bullying em uma escola de referência do Rio de Janeiro; 2) o papel da orientação educacional e da equipe escolar nas práticas de prevenção e enfrentamento do bullying. Por meio de uma pesquisa qualitativa na qual foram utilizados, como instrumentos de coleta de dados, a entrevista semiestruturada e a sondagem de opinião, foi possível analisar as formas de bullying presentes na instituição, sua relação com o preconceito e as práticas pedagógicas/ funções de cada agente participante da pesquisa no processo de manutenção, prevenção e enfrentamento do bullying.
\end{abstract}

PalaVRaS-ChaVe: bullying; preconceito; diálogo; orientação educacional

\begin{abstract}
This article refers to the master's research for the dissertation " The adult doesn't always resolve': educational guidance and the practices of bullying in the first years of elementary school." Addressed here are: 1) perceptions of school staff and students' parents on bullying in a reference school in Rio de Janeiro; 2) role of educational guidance and school staff in bullying prevention and coping practices. Through a qualitative research utilizing semistructured interview and opinion polling as instruments for data collection, it was possible to analyze forms of bullying in the institution, its relation to prejudice and pedagogical practices as well as the roles of each research participant in the process of maintenance, prevention and coping with bullying.
\end{abstract}

KEYWORDS: bullying; preconception; dialogue; educational guidance

${ }^{1}$ Colégio Pedro II (CPII). Rio de Janeiro, RJ, Brasil. e-mail: anacarolinahyer@gmail.com

2 Universidade do Estado do Rio de Janeiro (UERJ), Instituto de Aplicação Fernando Rodrigues da Silveira (CAp-UERJ), Programa de Pós-Graduação de Ensino em Educação Básica (PPGEB). Rio de Janeiro, RJ, Brasil. e-mail: claudiahbsonco@gmail.com 


\section{INTRODUÇÃO}

Em princípio, um dos sensos comuns sobre a escola é o de que ela é um lugar seguro para nossas crianças e jovens. Mas, infelizmente, nem sempre isso é verdade...

O bullying é um problema educacional e social que atinge milhares de estudantes em todo o mundo e é caracterizado como um tipo de violência escolar que ocorre entre pares de forma sistemática, resultando em uma relação desigual de poder entre 0 alvo e o praticante. As práticas violentas do bullying podem ser diversas e, via de regra, manifestam intolerância e preconceito às diferenças que constituem as identidades dos educandos. Várias são as pesquisas sobre o tema que indicam que 0 início dessa prática pode ser observado cada vez mais precocemente (ANTUNES, 2010; ANTUNES \& ZUIN, 2008; ESTEVES, 2015; ESTEVES \& ANDRADE, 2015; LOPES NETO, 2005; LOPES NETO \& SAAVEDRA, 2003;).

Nesse contexto, acreditamos que o serviço de orientação educacional, quando disponível na escola, pode ser um aliado para o planejamento e execução de estratégias de prevenção e enfrentamento ao bullying no cotidiano escolar, fundamentadas nos princípios de uma educação intercultural e para a tolerância (ANDRADE, 2009; CANDAU, 2011, 2012, 2014).

Para isso, é necessário conhecer a realidade da escola da qual se faz parte, com o objetivo de propor atuações de acordo com a demanda apresentada pela instituição.

A pesquisa de que se trata este artigo buscou conhecer a realidade dos anos iniciais do ensino fundamental de uma instituição de ensino considerada de referência no estado do Rio de Janeiro, no que diz respeito às práticas de bullying: a existência ou não desse fenômeno na escola pesquisada; as percepções de uma parcela da comunidade escolar sobre o bullying (equipe técnica e famílias dos educandos) e sua relação com o preconceito; e quais as possibilidades de atuação da orientação educacional para o enfrentamento e a prevenção do bullying no panorama apresentado.

\section{Planejamento metodológico da Pesquisa}

A pesquisa social qualitativa (MINAYO, 2013) realizada neste trabalho analisou as relações inerentes a uma determinada realidade da sociedade: as práticas/ percepções de bullying.

Após a realização da pesquisa bibliográfica e da análise documental, foram utilizadas diferentes técnicas de investigação para a coleta de dados perante os participantes da pesquisa. No recorte feito para este artigo, nos ateremos aos públicos para os quais foram escolhidas duas técnicas distintas de acordo com nossa avaliação da sua adequabilidade frente às características de cada público na sua relação com a escola. As entrevistas semiestruturadas foram usadas para buscar perceber e 
DOI: $10.12957 / \mathrm{e}-\mathrm{mosaicos} .2019 .43436$

compreender as percepções, crenças e ações dos profissionais que atuam na escola, como professoras, assistentes administrativos em educação, assistentes de alunos, diretora e orientadora educacional. A sondagem de opinião por meio de questionário com respostas fora do ambiente escolar foi escolhida para buscar perceber e compreender as percepções dos responsáveis pelos educandos.

No caso desta pesquisa, as entrevistas tiveram como finalidade obter dados a respeito do que pensa a comunidade escolar da instituição pesquisada sobre as práticas de bullying, como elas se apresentam (ou não) e quais são as estratégias de enfrentamento e prevenção realizadas nesse espaço escolar.

A sondagem de opinião foi elaborada mediante um questionário totalmente estruturado com perguntas e espaços para as respostas previamente determinados e fechados. Essa técnica foi utilizada para a construção de dados qualitativos de forma mais ágil mediante o preenchimento das informações pelos responsáveis pelos alunos, considerando o pouco tempo de presença desses atores no espaço escolar. 0 questionário é uma técnica muito usada para analisar uma ampla realidade, podendose destacar as ideias divulgadas pelo senso comum, permitindo uma análise comparativa das percepções dessa amostra com as difundidas socialmente a respeito do tema bullying.

A sondagem de opinião foi feita com os responsáveis dos/as educandos/as de duas turmas do $5^{\circ}$ ano do turno da manhã do primeiro segmento do Ensino Fundamental, que aceitaram participar da pesquisa. Dos 19 (dezenove) responsáveis que aceitaram participar da pesquisa, apenas 11 (onze) de fato devolveram 0 questionário preenchido.

No segundo momento, as entrevistas semiestruturadas foram aplicadas às professoras (cinco no total), aos assistentes de alunos do turno da manhã (dois funcionários), aos técnico-administrativos em educação (dois funcionários), à direção (uma diretora) e à orientadora educacional do $5^{\circ}$ ano (uma pedagoga). Sendo assim, onze profissionais da instituição participaram das entrevistas.

Reiteramos que a escolha de diferentes tipos de instrumentos para coletar os dados facilitou o processo de obtenção de informações, de acordo com a disponibilidade dos participantes para a pesquisa. No entanto, a utilização de instrumentos diversos para a coleta de dados, ao mesmo tempo em que amplia a abrangência da pesquisa (diferentes atores com diferentes relações com o espaço escolar), acaba por limitar em parte a análise, uma vez que diferentes instrumentos geram dados de qualidades diferentes: questionários $\mathrm{x}$ entrevistas.

Cabe ainda explicitar que, embora os instrumentos fossem diferentes, em todos, o conteúdo era semelhante e se dividia em categorias que se relacionavam. A divisão por categorias se deu, predominantemente, na seguinte ordem: identificação/perfil do grupo pesquisado, percepções de bullying pelo grupo pesquisado, a relação entre bullying e preconceito estabelecida pelos participantes do grupo analisado e, por fim, as práticas pedagógicas/ funções de cada agente da comunidade escolar (equipe e 
DOI: $10.12957 / \mathrm{e}-m o s a i c o s .2019 .43436$

famílias dos educandos) frente aos casos de bullying presentes na instituição escolar, bem como a visão de cada segmento sobre a atuação do setor de orientação educacional frente aos mesmos.

\section{AS PERCEPÇÕES DE BULLYING PELA EQUIPE ESCOLAR}

A equipe técnica participante desta pesquisa é dividida entre professoras e gestoras (orientação educacional e direção), assistentes em administração (que acompanham o recreio dos alunos) e assistentes de alunos (inspetores).

$\mathrm{Na}$ primeira parte da entrevista, na qual realizamos perguntas diretas aos participantes, ficou evidente que todos já apresentavam algum conhecimento prévio sobre o que era bullying. $\mathrm{E}$, de acordo com as suas falas, o bullying pode ser caracterizado como "uma brincadeira de mau gosto", "uma implicância repetitiva" que incomoda/desestabiliza o outro; agressões físicas e verbais que causam constrangimento, "piadinhas", "apelidos" e "adjetivos que desqualificam" e que, geralmente, envolvem características físicas; "atitudes incorretas", "desrespeitosas" e "erradas" que ocorrem de maneira sistemática no ambiente escolar. A exclusão (ser "posto de lado", "escolhido por último") também foi sinalizada como um tipo de bullying.

Frente aos conceitos estabelecidos pelos teóricos que pesquisam o tema, podem-se observar alguns equívocos na definição de bullying, como, por exemplo, considerá-lo limitado a "agressões verbais", como foi dito por uma professora: "Agressão verbal (...) não chega a ser uma agressão física (...), a agressão física já deixa de ser bullying para ser outra coisa." Ou a confusão com o assédio moral, como afirmou outra professora: "Agora, o bullying também existe do adulto para a criança, não aqui, mas já vi de professor para aluno". Além disso, um assistente de aluno relatou que "é qualquer tipo de situação que constrange uma outra pessoa, principalmente crianças.", afirmação genérica que pouco ajuda a compreender 0 fenômeno.

Por definição, o bullying é um tipo de violência (que pode ocorrer em outros espaços além da escola) que ocorre entre pares (no caso dessa pesquisa, entre educandos), não sendo restrita somente às agressões verbais, além de não ocorrer entre sujeitos com posições hierárquicas diferentes, como é o caso da relação entre professor e aluno.

Quanto à identificação dos participantes da prática de bullying, nove dos onze pesquisados afirmaram que saberiam identificar um possível alvo das atitudes violentas, sendo que, desse total, seis disseram já ter presenciado situações de bullying na instituição pesquisada.

As características dos alvos elencadas pelos participantes geralmente se remetem aos aspectos de fraqueza e fragilidade: "depressiva", "acuada", "retraída", "são muito tímidos, bem fechados", "sensível", "baixa autoestima", "nervoso", "se 
DOI: $10.12957 / \mathrm{e}-\mathrm{mosaicos} .2019 .43436$

sente inferior", "isolado" (se coloca separado do grupo), "agressivo", "chorosa", "triste", "envergonhada" e "insegura". Alguns destacaram o sentimento de falta de desejo do/a educando/a em ir à escola como um fator representativo do bullying. Para eles, quando a criança demonstra não gostar da escola ou não se importar em faltar às aulas, é algo significativo, que requer mais atenção por parte da instituição de ensino e das famílias.

Cabe destacar que, para alguns pesquisados, é nítido que existam diversos comportamentos dos alvos de bullying, pois cada pessoa é única, possui sua personalidade e encara as agressões de diferentes maneiras. Em especial, destaco a fala de uma professora que observou as diversas reações e perfis dos alvos de bullying em sua sala de aula:

Já identifiquei (...). A Anauá Caiuá ${ }^{\text {e }}$ o Jupi... tem a ver com o comportamento da criança... O Jupi é muito magrinho, pequenininho. Eles são muito tímidos, bem fechados, mas eu acredito que, em algum momento, eles tenham sofrido bullying sim. A Araci Leri sofrendo por conta de ser gordinha. Na turma (...), o que eu vejo é muito com o Iraí. Converso muito com a turma, mas ele é o mais massacrado ali. Mas o engraçado é que ele é uma criança que não se intimida, ele responde. Diferente da Anauá Caiuá e do Jupi. Eu nunca observei nitidamente a Anauá Caiuá e o Jupi sofrendo algum tipo de provocação, mas você nota que as crianças tratam eles de forma diferente. Eles são deixados de lado. E aí é uma coisa que é difícil, porque, se você presencia nitidamente o bullying, como é o caso do Iraí, você tem como intervir. Agora, fazer alguém gostar do outro é muito difícil, você não tem como fazer isso. (Professora 2).

Nessa fala, podemos observar dois tipos diferentes de alvo de bullying colocados pela professora, conforme as classificações citadas por Antunes (2010), Smith (2002), Fante (2005) e Olweus (1993): o passivo e o agressivo/provocador. O passivo, com um perfil mais tímido, sequer sinaliza que está sofrendo para a professora, mas é perceptível que há uma exclusão e um tratamento diferenciado para esses educandos. $O$ agressivo tem um perfil de revide, de não se intimidar com o outro e tentar se defender, muitas vezes, provocando o outro como forma de chamar a atenção para seu sofrimento (que pode ser provocado pelo bullying, ou decorrente de outras questões pessoais).

Além disso, fica explícita a classificação de dois tipos de bullying, mencionados por Lopes Neto (2005): o bullying direto (sofrido pelo aluno Jupi, segundo a professora), no qual é nítido que o educando está sofrendo agressões e isolamento, até porque, nesse caso, o próprio educando sinaliza para a professora; e o bullying

\footnotetext{
${ }^{3}$ Os nomes dos educandos foram trocados, a fim de garantir o sigilo dos participantes.
} 
DOI: $10.12957 / \mathrm{e}-m o s a i c o s .2019 .43436$

indireto, marcado principalmente pelo isolamento/ exclusão do educando e pelos tratamentos diferentes e sutis dos demais perante ele. Nesse caso, os alvos não verbalizam o que passam, sofrem em silêncio, tornando difícil o enfrentamento da situação com a colaboração dos professores.

Para além de uma classificação de tipos de bullying e seus possíveis alvos, a fala da professora nos coloca a pensar sobre uma questão crucial que é como lidar com essas questões no cotidiano escolar. É possível enfrentar algo que é visto, sentido e exposto, mesmo que as ações não sejam eficazes? Existe a possibilidade de se conhecer o que está ocorrendo e buscar algumas soluções/ propostas para a situação? Mas como enfrentar algo que é camuflado, "abafado" e, muitas vezes, até não admitido pela instituição escolar? Como lidar com essa situação tão delicada sem causar exposição e constrangimento aos envolvidos? E mais, sem colocar "lenha na fogueira", pois, às vezes, parece que é mais "fácil" ignorar o que ocorre para evitar que algumas questões venham à tona. É necessário ir além, mas de que forma? A professora disse que "Fazer alguém gostar do outro é muito difícil, você não tem como fazer isso", então como a educação pode contribuir para a aceitação do outro, da maneira como ele é (a consciência de que eu sou um outro) no ambiente escolar, para não reforçar preconceitos e intolerâncias que podem ocasionar o bullying?

É nesse contexto que a defesa por uma ética civil proposta por Cortina (1996) e Andrade (2009) pode contribuir para a aceitação das diferenças. Se o educando não consegue gostar ou ter sentimentos que vão além do respeito para com o outro, ele deve ao menos (por meio de uma exigência garantida pela instituição), ter atitudes de tolerância e respeito para com ele.

A atuação dos educadores seria promover mediação das relações, observando as práticas dos educandos e propondo intervenções necessárias, quando o limite das normas da boa convivência estabelecidas por meio de consensos racionáveis fosse ultrapassado. O "fazer alguém gostar do outro" poderia ser proposto como uma forma de convite, mas não como uma exigência, uma obrigação. O educador poderia atuar utilizando estratégias persuasivas para favorecer uma possível interação mais profunda entre seus educandos, mas somente se todos estiverem disponíveis para 0 estabelecimento dessa relação. Como exigência, cabe ao educador, conforme quesito mínimo, contribuir para a promoção do respeito e tolerância a todos. Os vínculos e laços de amizades podem ser favorecidos e incentivados, mas nunca obrigados e exigidos, isso caberia somente às escolhas dos/as educandos/as.

Quanto à identificação dos possíveis praticantes de bullying, declararam ser mais fácil detectar quem promove as ações violentas e intimidadoras, embora nem todos já tivessem presenciado uma situação de bullying na escola; foi unânime que todos saberiam identificar quais seriam os comportamentos e atitudes de um "bully". Dentre as características atribuídas aos praticantes de bullying, destacaram-se: "desrespeitosos", "agressivos", "provocadores", "desafiadores", "violentos", "implicantes", que fazem "brincadeiras de mau gosto", "desestabilizam/perseguem a 
DOI: $10.12957 / \mathrm{e}-\mathrm{mosaicos} .2019 .43436$

vítima", "apresentam algum tipo de preconceito", bem como "dificuldade de relacionamento".

Uma de nossas entrevistadas acredita que os praticantes de bullying também sofrem, pois eles, geralmente, convivem em ambientes em que não são ouvidos nem respeitados; sendo assim, eles reproduziriam, nas práticas de bullying, a forma como são tratados, indo ao encontro da análise realizada por Pereira (2002), Pinheiro (2006) e Smith (2002), que analisam a família e a própria escola como sendo ambientes hostis que podem favorecer o comportamento agressivo das crianças e adolescentes em casos específicos.

Em relação ao conhecimento da legislação sobre bullying pela equipe escolar, a maioria relatou que desconhece as leis sobre o tema. Os que declararam já terem "ouvido falar" algo a respeito disseram que não sabiam o conteúdo destas. Praticamente todos relataram que seria importante a divulgação dessas leis pela equipe escolar como uma forma de explicitar a importância da discussão sobre o tema, resguardar a instituição e alertar/ prevenir possíveis atitudes de bullying dos educandos, pois uma lei sobre o assunto legitima a seriedade com que deve ser tratado esse tema.

Sobre a legislação sobre o tema, destacam-se duas leis, a Lei Federal $n^{\circ} 13.185$, de 6 de novembro de 2015, e a Lei n 6.401/13, de 5 de março de 2013, para o Estado do Rio de Janeiro, bem como a importância de existir uma legislação específica que aborde a violência escolar e o bullying. A criação dessas leis corrobora a necessidade de apoio às instituições escolares, no que diz respeito ao enfrentamento e à prevenção de um desafio que faz parte de seu cotidiano: o bullying. $\mathrm{E}$, mais do que dar apoio às escolas, ela representa um apoio aos educandos, que podem contar com mais um meio de garantir sua segurança e integridade no espaço escolar, pois, segundo a obrigatoriedade exigida na lei (especificamente na lei nacional), a instituição de ensino, bem como seus gestores e demais profissionais, devem propor ações que contribuam para a prevenção de novo caso e para o enfrentamento dos casos já existentes.

A relação entre bullying e preconceito foi exposta nas perguntas diretas sobre o tema e também em outros momentos da entrevista, como nas perguntas relacionadas às percepções de bullying (definição de bullying, identificação de alvos e praticantes, etc.) e às vivências das práticas de bullying pelos participantes na instituição ou fora dela (observação de bullying na instituição escolar, tipos/práticas de bullying que conhecem, apelidos, etc.). Ficou evidente que alguns participantes consideram o preconceito como uma das motivações que podem levar às práticas de bullying, além de ele também aparecer implícito em algumas práticas como, por exemplo, nos apelidos considerados pejorativos pelos participantes.

Algumas falas evidenciam essa relação: "bullying é (...) uma ação (...) que tem cunho preconceituoso" (sobre a definição de bullying); "a criança já apresenta algum tipo de preconceito e acaba jogando a frustração dela no outro" (sobre as atitudes de um praticante de bullying); "tem aquelas coisas do gordinho, de repente, do negro 
DOI: $10.12957 / \mathrm{e}-\mathrm{mosaicos} .2019 .43436$

$(\ldots)^{\prime \prime}$, "crianças com problemas neurológicos (...), toma medicamento, é vítima de bullying", "a pessoa é caolha, tem cabelo diferente, usa óculos..." (sobre o perfil dos alvos de bullying); "apelido que envolve características físicas", "quatro olhos, rolha de poço, gorda", "cabelo duro" (sobre apelidos pejorativos relacionados às características predominantemente físicas decorrentes de ideias preconceituosas).

A primeira pergunta direta sobre a relação do bullying com o preconceito, foi se eles concordavam com afirmação de Barreiros (2006), de que "o bullying é uma das expressões violentas do preconceito". Todos os entrevistados concordaram com a afirmação: "não aceitar o outro da forma como ele é, é um tipo de preconceito sim", "eu acho que é um preconceito sim por esta questão de ser uma ideia que a pessoa cria sem fundamento, porque preconceito para mim é isso: você cria uma ideia que você acha que é certa e que estereotipa e coloca dentro de uma generalização e você acha que todo mundo tem que ser daquela maneira e não é assim", "vem do preconceito sim e da falta de empatia", "pode ser preconceito de alguma coisa no corpo da pessoa", "tanto pode ser preconceito, quanto racismo", "o bullying coloca para fora tudo que aquela pessoa já tem." Alguns fizeram ressalvas: "eu acho que nem sempre o bullying é preconceito", "acaba sendo um preconceito em alguns casos (...) vai além, é um desrespeito.", "não só do preconceito, mas também de tudo". Entendemos que essas falas apontam que o entendimento desses entrevistados seria de que o bullying não é apenas uma expressão do preconceito, mas o incluiria.

Em algumas falas, ficou explícita a relação entre as definições de preconceito, por parte dos participantes e as definições de preconceito de teóricos que abordam o tema. "O preconceito é uma ideia pré-concebida", disse uma professora. Tal ideia vai ao encontro da proposta inicial de definição do preconceito proposta por Allport (1954), quando afirma que o preconceito está relacionado ao desconhecido; quando a pessoa não conhece algo, cria mecanismos psicológicos de aproximação para elaborar um conceito com algo que ela já vivenciou (ou familiar), porém essa aproximação nem sempre encontra correspondência na realidade. Essa diferença entre a realidade e a ideia (que ainda está sendo elaborada) que a pessoa faz de algo seria o que determinaria o preconceito.

Outra professora destacou que a segregação pode ocasionar o bullying e preconceito, e, portanto, precisamos nos atentar para a dificuldade que as pessoas têm em lidar com as diferenças, a fim de amenizar possíveis consequências mais graves.

Existem várias verdades sobre uma mesma história, então lidar com as diferenças, com as várias verdades que existem, acho que esse é o grande ponto. Como as pessoas não sabem lidar com isso, porque não aceitam ninguém diferente delas, eu acho que é aí que vem o bullying, é aí que vem o preconceito, a violência, seja verbal ou física. (Professora 2) 
DOI: $10.12957 /$ e-mosaicos.2019.43436

A busca pela verdade é um princípio ético inerente às relações humanas, porém o intolerante é "aquele que pensa possuir ' $a$ ' verdade e se sente impulsionado, pela mesma verdade, a impô-la a outros." (ANDRADE, 2009, p.129). Ou seja, aquele/a educando/a que não tolera o outro, por preconceito a alguma característica que faz parte de sua identidade e possui atitudes agressivas (até bullying) com o outro por conta disso, acredita que o que ele pensa seja o ideal, um padrão que todos deveriam seguir, pratica uma forma de autoritarismo, de estabelecer uma relação desigual de poder.

\section{O PAPEl dA EQUIPE ESCOLAR NAS PRÁticas de PREVEnÇão E ENFRENTAMENTO DO BULLYING}

As práticas de bullying citadas pelos participantes são caracterizadas principalmente por ofensas verbais (apelidos) e de exclusão, que expressam preconceitos e enfatizam, de forma negativa, características físicas e de personalidade dos alvos.

Os meninos que estavam atrás dela, estavam a chamando de Patinho Feio, e falando do cabelo, falando das características físicas dela. (Professora 4)

Um aluno do $5^{\circ}$ ano, no ano retrasado, I., ele soube que tinha um menino na sala dele que era espírita e ele começou a bater nesse menino e disse que batia porque ele era espírita e ele não aceitava, e que ele tinha vontade de matar todos os espíritas, os negros e os gays.(...) várias pessoas da sala de aula se sentiram ofendidas porque se acharam nesse grupo que ele não gostava. (Professora 3 )

Uma lidera o grupo e fala para as outras: - Não deixa a fulana brincar. (...) ela é suja, tem piolho, não sabe brincar. (Técnico Administrativo 2)

Crianças com apelidos desrespeitosos ou isolados porque eram de uma classe diferente da do praticante. (Diretora)

Tem vários casos em que a criança é gorda, em que a criança tem cabelo assim e assado. (Professora 5)

Os participantes, além de citarem os casos de bullying que já presenciaram, responderam o que foi feito pela instituição (e por eles) nessas situações, alguns também relataram práticas cotidianas na escola, que podem contribuir para a prevenção desse problema. Para a maioria dos casos (os que já ocorreram e os que ainda ocorrem), é relatado que o diálogo é e foi a melhor ferramenta de ajuda para lidar com essas atitudes. O diálogo também colaborou para o descobrimento de algumas situações de bullying na instituição.

A J. (orientadora) conversou com a criança (o alvo), conversou comigo, conversou com o menino (o praticante), chamou os pais de ambos 


\section{(...). (Professora 3)}

Nosso papel maior é promover, dentro da instituição, o diálogo, porque é através do diálogo, se aproximando e conhecendo a criança, que se tem como perceber se houve uma mudança de atitude e como essa criança está. $E$, quanto mais ela criar uma condição de confiança, ela vai se sentir mais à vontade para manifestar o que pensa. (Diretora)

Geralmente, o diálogo entre a equipe escolar e os estudantes gira em torno da questão da empatia, de se colocar no lugar do outro para não cometer atitudes que não gostariam de sofrer. Alguns relataram que a abordagem por meio da empatia já trouxe bons resultados, auxiliou os/as estudantes a compreenderem que suas atitudes estavam inadequadas e poderiam agredir seus colegas, trazendo consequências graves para ambos. Porém, tal abordagem necessita ser constante, "trabalho de formiguinha", a fim de que a criança internalize as regras de convivência e respeito ao próximo e adquira consciência dos seus atos, bem como as possíveis consequências deles.

A maioria dos casos citados pelos entrevistados abordavam ações de enfrentamento ao bullying, porém somente quando ele já estava instalado. Aparentemente, não há uma prática de prevenção permanente específica contra o bullying, e as práticas de combate ocorrem de maneira isolada, quando algum caso é descoberto (seja pela observação/ presenciar o ato, seja por meio dos relatos dos/as estudantes).

Além do diálogo pela construção da empatia, os participantes alegaram que consideram como uma forma de prevenção ao bullying as abordagens (em sala de aula e outros espaços) sobre a valorização e respeito às diferenças e a todos, bem como o combate ao preconceito.

A participação da família foi levantada por alguns participantes que acreditam que a escola deve buscar parceria e apoio para lidar com as situações de bullying que surgem no cotidiano escolar: "Eu acho que o bullying não é só da escola, tem que ser um trabalho integrado da escola com a família. É ilusão achar que a escola sozinha dá conta." - disse uma professora.

Em relação aos técnicos administrativos, segundo suas falas, o maior contato com os/as estudantes é durante o recreio, é nesse momento que eles presenciam alguns conflitos entre os estudantes. Para lidar com tais situações, eles afirmaram que não tiveram nenhum preparo específico, mas utilizam o bom senso para lidar com as questões que aparecem, usam o diálogo para entender e solucionar os casos, mas, na maioria, quando não existe um consenso (solução, para eles), eles encaminham os educandos para o setor de orientação educacional ou para a direção, dependendo de sua gravidade e recorrência.

Quanto à equipe gestora (orientação educacional e direção), seu papel no combate e prevenção ao bullying está direcionado ao apoio aos demais profissionais 
DOI: $10.12957 / \mathrm{e}-\mathrm{mosaicos} .2019 .43436$

da escola, bem como em gerir projetos que contribuam para a abordagem desse tema, incluindo o Projeto Político-Pedagógico da instituição. "Contribuir trabalhando junto com todas as equipes desenvolvendo um projeto político-pedagógico (...), para que o bullying apareça como algo importante a ser encarado e trabalhado por todos os profissionais da escola" - afirmou a diretora.

Dessa forma, pode-se concluir que a orientação educacional, além de participar das atividades estipuladas pelo projeto pedagógico (incluindo a realização dos projetos citados pela equipe gestora), atuaria conforme os princípios fundamentais da orientação educacional: ouvindo a comunidade escolar, orientando os educandos, professores e famílias. Além de propor alternativas junto a todos os envolvidos, nas situações em que o bullying já se encontra presente e também nas ações de prevenção, junto à equipe escolar, famílias e educandos.

Ao serem questionados sobre quais profissionais deveriam estar diretamente ligados às ações de prevenção e combate ao bullying, a maioria dos participantes acredita que todos na escola devem contribuir de alguma forma. Porém há uma prevalência em afirmarem que os professores (por suas formações acadêmicas e passarem mais tempo com as crianças na escola) seriam talvez os mais preparados e disponíveis para a abordagem do tema em sala de aula, seguidos pelos demais profissionais da equipe pedagógica.

Acreditamos que a escuta de diferentes ideias e concepções/percepções de bullying e como se dão as relações nesse espaço escolar possibilita a abertura para um diálogo que busca um consenso entre todos, sobre o que é considerado importante e essencial para a formação de educandos cidadãos tolerantes e participativos no enfrentamento das práticas preconceituosas e discriminatórias de valor.

\section{AS PERCEPÇõES DE BULLYING PELAS FAMÍLIAS DOS EDUCANDOS}

A escolha por "ouvir" também as famílias dos educandos foi devido ao trabalho que o setor de orientação desenvolve com esse segmento da comunidade escolar. Como uma de suas atribuições, a orientação atua como mediadora da relação entre família e escola, portanto ouvir os responsáveis seria essencial para se descobrir o que eles pensam sobre o bullying e sobre a instituição de ensino frente a essa realidade. Quais as contribuições das famílias para a elaboração de medidas de prevenção e enfrentamento ao bullying que poderiam ser realizadas pela escola?

Todos os responsáveis declararam que já conheciam o tema bullying e relataram que este é caracterizado por situações agressivas (verbais, físicas e/ ou emocionais) que ocorrem de forma repetitiva contra um ou mais colegas. Tais situações representam um desrespeito ao outro, e esse outro se sente humilhado e desrespeitado, ofendido. Muitas vezes, o bullying, para eles, é "mascarado" como "brincadeiras inocentes". Alguns exemplos de práticas violentas de bullying foram: xingamentos, apelidos ofensivos, socos, empurrões, tapas, ameaças, exclusão, 
DOI: $10.12957 / \mathrm{e}-\mathrm{mosaicos} .2019 .43436$

deboche, racismo, comentários depreciativos e preconceitos diversos.

De acordo com esses dados, aparentemente, os responsáveis dos educandos apresentam um conhecimento prévio que está de acordo com as definições/conceitos e características do bullying, segundo as pesquisas sobre o tema. E, mais uma vez, aparece a relação entre as práticas violentas do bullying com as brincadeiras inerentes à infância, porém, no caso dos responsáveis, eles fizeram uma distinção clara entre ambas situações.

A maioria dos responsáveis acredita que exista bullying na instituição pesquisada. Eles alegaram que, como a escola é um ambiente propício à convivência entre diversos tipos de pessoas, ou seja, em que as diferenças estão presentes, geralmente os conflitos se tornam naturais.

Dois responsáveis relataram que seus filhos já foram alvo de bullying; "meu filho passou por isso: 'cabeção' e isolamento no 'recreio"'; "minha filha sempre reclama de algum colega que fica colocando apelidos feios que a ofendem.".

De acordo com os relatos dos responsáveis, aparentemente, o tipo predominante de bullying que ocorre na instituição é o indireto, aquele que corresponde às práticas de isolamento social, exclusão. E as formas de violência cometidas são, principalmente, a verbal e simbólica, com o uso de provocações verbalizadas e a utilização de apelidos pejorativos e ofensas contra o alvo.

Quanto à relação entre bullying e preconceito, todos disseram que consideram o bullying como uma expressão do preconceito. Inclusive, na definição do bullying, alguns participantes já relacionaram esses dois conceitos: "Situações em que características como raça, cor, tipo físico, são objetos de comentários depreciativos e etc.; e preconceitos diversos, principalmente religioso e de orientação sexual"; "exemplo: palavras preconceituosas"; "racismo, apelidos que ofendem, deboche, preconceito."

Os responsáveis relataram que, geralmente, o que não é consenso entre a maioria, o que para eles pode ser considerado como "o diferente" é tratado de forma preconceituosa e desrespeitosa. Eles creem que o bullying se manifesta por meio do uso de expressões preconceituosas, que demonstram um juízo de valor pejorativo, bem como o tratamento ao outro através de apelidos.

Sempre é demonstrado pelas características que a criança possui. Ex: gordinho, dentuço. (Responsável 1)

Porque são pessoas que não sabem lidar com as diferenças. (Responsável 2).

Dependendo do contexto pode ser sim, o negro, o deficiente, o menos favorecido, entre outros, podem sofrer preconceito/bullying. (Responsável 3).

Muitas vezes sim, o preconceito com os gordos, homossexuais, negros, nós vemos muitos casos destes, até mesmo dentro da escola. (Responsável 6). 
A intolerância e o desrespeito às diferenças também foram mencionados pelos participantes como uma das formas de apresentação do bullying.

\section{AS AÇÕES DA EQUIPE ESCOLAR FRENTE AO BULLYING: AS PERCEPÇÕES DAS FAMÍLIAS}

As famílias reconhecem que a instituição de ensino realiza ações de prevenção e enfrentamento ao bullying. Relataram que o assunto é abordado, em sala de aula, pelos professores, incluindo atividades (como campanhas) realizadas pelos próprios educandos. Além disso, disseram que a escola já promoveu palestras e reuniões de pais sobre o assunto, voltadas especificamente para o esclarecimento das famílias sobre essa temática, embora nem todos pudessem ter participado.

Os responsáveis destacam a importância da capacitação dos profissionais da escola sobre o bullying. A maioria relata que existe uma preocupação dos profissionais em estarem atentos para essa questão e para possíveis práticas de bullying que pode ocorrer na escola. Os professores, o setor de orientação e a direção, segundo os participantes, atuam de forma efetiva, quando existe algum caso de bullying, principalmente por meio da prática do diálogo com os educandos: "os professores sempre falam do assunto em reunião de pais"; "Fui muito ajudada pelo setor de orientação e pela direção"; "eu mesma já parei para ler cartazes muito interessantes no setor de orientação e os professores também falam com os alunos"; "os professores que estão relacionados com o setor de orientação (atuar na abordagem do bullying)", entre outras justificativas.

Quanto aos profissionais que devem atuar diretamente com a prevenção e o enfrentamento do bullying na instituição, a maioria dos participantes defendeu que todos os profissionais que têm contato com os educandos deveriam contribuir de alguma forma para a concretização dessas ações, mas destacou que os professores e a orientação educacional, seriam os principais responsáveis.

A última pergunta abordava se eles consideravam importante a participação das famílias para a prevenção e o enfrentamento do bullying na escola, e a maioria concordou que suas participações fazem parte desse processo educacional.

Os responsáveis também destacaram a importância de se ter uma instituição de ensino que esteja aberta ao diálogo com as famílias, que busque e promova a integração entre escola e família. Essa parceria seria benéfica do ponto de vista específico do bullying, pois ambas atuariam em conjunto: a família seria comunicada sobre possíveis casos de bullying e receberia orientações da escola, bem como esta contaria com a colaboração dos familiares, tanto dos que sofrem, quanto dos que praticam e ainda dos que assistem práticas de bullying, para apoiarem a realização das possíveis estratégias elaboradas em conjunto por ambas, para o enfrentamento das práticas de bullying. Para isso, os participantes realçam a necessidade e a importância do diálogo entre todos na instituição de ensino. 


\section{CONSIDERAÇÕES FINAIS}

Esta pesquisa possibilitou a confirmação da existência de práticas de bullying já nos anos iniciais do ensino fundamental, apesar de que a maioria das pesquisas sobre o tema afirme que o bullying ocorre predominantemente a partir do $2^{\circ}$ segmento do ensino fundamental. No projeto da pesquisa, sinalizávamos a necessidade de intervenções de prevenção nesse segmento, no entanto, verificamos a necessidade também de atuação já em casos concretos.

Observamos também que houve convergências e divergências de percepções sobre a ocorrência de bullying entre os diferentes grupos participantes da pesquisa (famílias e equipe escolar). As divergências encontradas, assim como a realidade de bullying apresentada, nos induzem à reflexão sobre a necessidade de uma sistematização de atividades que promovam ações de prevenção e enfrentamento ao bullying nessa escola, como uma das atribuições do setor de orientação, em parceria com os demais departamentos da instituição, por meio da mediação e integração entre todos.

A hipótese inicial de que o preconceito é o ponto de partida das manifestações de bullying confirmou-se. Desse modo, a promoção do diálogo sobre todas as formas de preconceito mostrou-se como uma alternativa potente para o enfrentamento desse problema.

A pesquisa também aponta que a orientação educacional, em uma perspectiva de educação voltada para a formação de cidadãos plenos, dignos e tolerantes, necessita estar atenta aos desafios atuais da educação, entre os quais, o bullying. Como alternativa em comum, colocada por todos os participantes da pesquisa para esse caminho, está o diálogo. As futuras ações de prevenção e enfrentamento realizadas pelo setor de orientação devem ser realizadas de acordo com a escuta atenta de todos os participantes da comunidade escolar, em especial, os estudantes, sujeitos de outra pesquisa sobre o tema.

\section{REFERÊNCIAS}

ALLPORT, G. The nature of prejudice. Boston: The Beacon Press, 1954.

ANDRADE, Marcelo. Tolerar é pouco? Pluralismo, mínimos éticos e prática pedagógica. Rio de Janeiro: Novamerica, 2009.

ANTUNES, D. C. Bullying: razão instrumental e preconceito. São Paulo: Casa do Psicólogo, 2010. 
DOI: $10.12957 /$ e-mosaicos.2019.43436

ANTUNES, D. C. \& ZUIN, A. A. S. Do bullying ao preconceito: os desafios da barbárie à educação. Revista Psicologia e Sociedade. v. 20, n. 1. Porto Alegre. Jan/Abril, 2008.

BRASIL. Lei $n^{\circ}$ 13.185, de 6 de novembro de 2015.

Institui o Programa de Combate à Intimidação Sistemática (Bullying). Disponível em: http://www.planalto.gov.br/ccivil_03/_ato2015-2018/2015/lei/l13185.htm Acesso em: 11 jun. 2019.

BRASIL. RIO DE JANEIRO. Lei estadual $n^{\circ}$ 6.401/13, de 5 de março de 2015. Institui a "semana de combate ao bullying e ao cyberbullying" nas escolas públicas da rede estadual do Rio de Janeiro, altera a Lei estadual no 5.645, de 6 de janeiro de 2010, e dá outras providências. Disponível em: https://gov-

rj.jusbrasil.com.br/legislacao/1034304/lei-6401-13 Acesso em: 11 jun. 2019.

CANDAU, Vera Maria (org.). Diferenças culturais e educação: construindo caminhos. Rio de Janeiro: 7letras, 2011.

(coord.). Somos todos iguais? Escola, discriminação e educação em direitos humanos. 2. ed. Rio de Janeiro: Lamparina, 2012.

. Professor/a: profissão de risco? Rev. Novamérica, Ed. n 118. Disponível em http://www.novamerica.org.br/revista_digital/L0118/rev_emrede.asp. Acesso em 20 de setembro de 2014

CORTINA, Adela. Ética civil e religião. São Paulo: Paulinas, 1996.

ESTEVES, P. \& ANDRADE, M. Bullying: intolerância e banalidade silenciam as diferenças na escola. In: ANDRADE, M. (org.). Diferenças silenciadas: pesquisas em educação, preconceitos e discriminações. 1. ed. Rio de Janeiro: 7letras, 2015.

ESTEVES, P. A escola não é um lugar fácil... não mesmo!: bullying, não reconhecimento da diferença e banalidade do mal. Tese de doutorado em Educação - PUC do Rio de Janeiro, Rio de Janeiro, 2015.

FANTE, C. Fenômeno bullying: como prevenir a violência nas escolas e educar para paz. 2. ed. Campinas: Versus, 2005.

LOPES NETO, A. A. Bullying - comportamento agressivo entre estudantes. In: Jornal de Pediatria. Rio de Janeiro, v. 81, n.5, 2005.

LOPES NETO, A. A. \& SAAVEDRA, L. H. Diga não para o bullying - Programa de redução do comportamento agressivo entre estudantes. Rio de Janeiro. ABRAPIA, 2003. 
DOI: $10.12957 /$ e-mosaicos.2019.43436

MINAYO, M. C.S. Pesquisa Social: Teoria, método e criatividade. Petrópolis, RJ: Vozes, 2013.

OLWEUS, D. Bullying at school: what we know and what we can do. United Kingdom: Blackwel publishing, 1993.

PEREIRA, B. O. Para uma escola sem violência: estudo e prevenção das práticas agressivas entre crianças. Porto: Fundação Calouste Gulbenkian, 2002.

PINHEIRO, F. M. F. Violência intrafamiliar e envolvimento em bullying no ensino fundamental. 2006. 148 f. Dissertação (Mestrado em Educação Especial). Centro de Educação e Ciências Humanas, Universidade Federal de São Carlos. São Carlos.

SMITH, P.K. Intimidação por colegas e maneiras de evitá-la. In: DERBARBIEUX, E. BLAYA, C. (orgs.). Violência nas escolas e políticas públicas. Brasília: UNESCO, 2002, p. $187-205$.

Recebido em 20 de abril de 2019

Aceito em 17 de julho de 2019

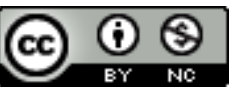

A e-Mosaicos Revista Multidisciplinar de Ensino, Pesquisa, Extensão e Cultura do Instituto de Aplicação Fernando Rodrigues da Silveira (CAp-UERJ) está licenciada com uma Licença Creative Commons - Atribuição-NãoComercial 4.0 Internacional.

Os direitos autorais de todos os trabalhos publicados na revista pertencem ao(s) seu(s) autor(es) e coautor(es), com o direito de primeira publicação cedido à e-Mosaicos.

Os artigos publicados são de acesso público, de uso gratuito, com atribuição de autoria obrigatória, para aplicações de finalidade educacional e não-comercial, de acordo com o modelo de licenciamento Creative Commons adotado pela revista.
} 